\title{
Association of the programmed cell death-1 PD1.5 C>T polymorphism with cervical cancer risk in a Chinese population
}

\author{
X.F. Li ${ }^{1}$, X.Q. Jiang ${ }^{2}$, J.W. Zhang ${ }^{3}$ and Y.J. Jia ${ }^{1}$ \\ ${ }^{1}$ Department of Gynecology, \\ Weifang Traditional Chinese Hospital, Wei Fang, China \\ 2Department of Obstetrics and Gynecology, \\ Weifang Maternity and Child Care Hospital, Wei Fang, China \\ 32Department of Obstetrics and Gynecology, \\ Hanting District People's Hospital of Weifang, Wei Fang, China \\ Corresponding author: Y.J. Jia \\ Email: jiayoujuandoctor@126.com \\ Genet. Mol. Res. 15 (1): gmr.15016357 \\ Received August 19, 2015 \\ Accepted November 26, 2015 \\ Published March 24, 2016 \\ DOI http://dx.doi.org/10.4238/gmr.15016357
}

ABSTRACT. The association of the programmed cell death-1 PD1.5 C>T polymorphism with cervical cancer risk has not been investigated. In this hospital-based case-control study, we analyzed 256 patients with cervical cancer and 250 healthy controls. Pearson chi-square test was used to examine differences in the distribution of genotypes between cases and controls. Association between the polymorphism and the susceptibility to cervical cancer was evaluated using unconditional logistic regression analysis. This revealed that the frequencies of the three genotypes (CC, CT, and TT) in cervical cancer cases and controls were 17.58, 65.23, and $17.19 \%$ and $24.80,40.40$, and $34.80 \%$, respectively; the difference between the two groups was significant $(P<0.001)$. We found that the CT genotype was significantly associated with increased cervical cancer risk (adjusted $\mathrm{OR}=2.18 ; 95 \% \mathrm{Cl}=1.37-6.11 ; \mathrm{P}=0.009$ ). Moreover, there was significant association between $\mathrm{PD}-1.5 \mathrm{C} / \mathrm{T}$ polymorphism and susceptibility to cervical 
cancer under dominant model $(\mathrm{OR}=1.27,95 \% \mathrm{Cl}=1.01-2.15, \mathrm{P}=0.047)$. We conclude that the PD-1.5 C/T polymorphism may be associated with increased risk of cervical cancer. The study also highlights the importance of conducting genetic association studies in different ethnic populations.

Key words: Programmed death 1; Single nucleotide polymorphism; Cervical cancer; Incidence; Case-control study

\section{INTRODUCTION}

Cervical cancer is the third most commonly diagnosed cancer and the fourth leading cause of cancer death in women, accounting for $9 \%(529,800)$ of all new cancer cases and $8 \%(275,100)$ of all cancer deaths among women in 2008 in the world (Jemal et al., 2011). The important roles of genetic factors in cervical cancer pathogenesis are underscored by the findings that cervical cancer exhibits a significant familial clustering; first degree relatives of patients have double the risk of developing cancer (Magnusson et al., 1999). A few risk-modulating variants for cervical cancer have been identified by a candidate gene association study. The genes that are associated with cervical cancer susceptibility are involved in DNA repair, cell cycle and apoptosis, cell proliferation and differentiation, the human leukocyte antigen system, and various immune responses (Ferguson et al., 2012; Safaeian et al., 2012).

The human programmed death-1 (PD-1) gene, which encodes the PD-1 protein, is located on chromosome 2q37.3. A role for PD-1 in human diseases was first proposed in genetic studies reporting a correlation of $\mathrm{PD}-1$ polymorphisms with susceptibility to systemic lupus erythematosus (SLE) (Prokunina et al., 2002). Following this, many researchers began to study the potential impact of PD-1 variants on the pathogenesis of several autoimmune diseases, including ankylosing spondylitis (AS), SLE, rheumatoid arthritis (RA), and type 1 diabetes (T1D) (Bertsias et al., 2009; Tahoori et al., 2011; Qian et al., 2013). However, little is currently known about the role of PD-1 genetic variants in cancer to date.

Previously, Mojtahedi et al. (2012) found that the PD-1.5 C/T polymorphism was significantly associated with colon cancer. Hua et al. (2011) found that heterozygosity of the CT allele of PD-1.5 was present at a lower frequency in breast cancer cases in comparison with controls $(P=0.004)$, and the frequencies of $C C$ genotype and $C$ allele were higher in breast cancer cases $(P=0.003$ and $P=0.010$, respectively). Moreover, the $C C$ genotype and the $C$ allele might play a potential risk role in breast cancer (Hua et al., 2011). Savabkar et al. (2013) found that the PD-1.5 C/T polymorphism might affect gastric cancer risk and prognosis in an Iranian population. However, the association of the PD-1.5 C>T polymorphism with cervical cancer risk has not been investigated. Therefore, in the present study, we sought to determine the association between PD$1.5 \mathrm{C}>\mathrm{T}$ polymorphism and cervical cancer risk in a Chinese population.

\section{MATERIAL AND METHODS}

\section{Study population}

In the present case-control study, a total of 256 patients with a determined stage, histological grade, and cervical tumor type, based on the International Federation of Gynecology 
and Obstetrics (FIGO) staging system, were included between May 2012 and February 2014 in the Department of Gynecology, Weifang Traditional Chinese Hospital. Two hundred fifty healthy female controls were recruited when they were attending a clinic for routine examination. All individuals were interviewed by trained nurse-interviewers using a structured questionnaire that detailed their age, body mass index (BMI), and menopausal status. Informed consent was obtained from all patients and control subjects. The study methods were approved by the local Ethical Committee of the Weifang Traditional Chinese Hospital.

\section{DNA extraction and genotyping}

A 5-mL sample of venous blood was collected from each subject into a test tube containing EDTA as anticoagulant. Genomic DNA was extracted from peripheral whole blood using High Pure PCR Template Preparation Kit according to the manufacturer protocol. Nested polymerase chain reaction-restriction fragment length polymorphism (nested PCR-RFLP) method was used for determination of the C/T polymorphism status at the PD-1.5 position. The PCR products were then subjected to an RFLP reaction with restriction enzyme $P$ vull and incubated at $37^{\circ} \mathrm{C}$ overnight. Finally, the products were analyzed using $3 \%$ agarose gel electrophoresis and ethidium bromide staining. The resulting bands were $89 \mathrm{bp}(\mathrm{CC})$, or two fragments of 48 and $41 \mathrm{bp}$ (TT).

\section{Statistical analysis}

Genotype frequencies in the control group were checked for the Hardy-Weinberg equilibrium by using a goodness-of-fit $\chi^{2}$-test. Pearson Chi-square test was used to examine distribution difference of genotypes between cases and controls. Association between the polymorphism and the susceptibility to cervical cancer was evaluated using unconditional logistic regression analysis, adjusted by age, age at first sexual intercourse, and smoking status. These statistical analyses were done with the SPSS software program (version 18.0, SPSS Inc., Chicago, IL, USA). All statistical tests were two-sided and a P value of less than 0.05 was used as the criterion of statistical significance.

\section{RESULTS}

\section{Characteristics of cervical cancer patients and controls}

The frequency distribution of general characteristics of the cervical cancer patients and controls is presented in Table 1. There was no significant difference between the two groups in terms of age distribution $(P=0.711)$ suggesting that matching of subjects based on this variable was adequate. There was no significant difference between cases and controls in the distribution of age at primiparity $(P=0.304)$. Nevertheless, as shown in Table 1, HPV infection $(P<0.001)$ and smoking status $(P=0.004)$ were associated with a significantly increased risk of cervical cancer.

\section{Genotypes and alleles frequencies of the PD1 gene polymorphism (PD-1.5 C/T) among cervical cancer patients and controls}

We detected three genotypes for the PD-1.5 C/T polymorphism, including $\mathrm{CC}, \mathrm{CT}$, 
and TT, among the Chinese Han women. The genotype distribution in the control group was in Hardy-Weinberg equilibrium $(P>0.05)$. The allele and genotype frequencies of the PD-1.5 C/T polymorphism are summarized in Table 2. Specifically, the frequencies of the three genotypes (CC, CT, and TT) in cervical cancer cases and controls were 17.58, 65.23, 17.19\% and 24.80, 40.40, and $34.80 \%$, respectively; the difference between the two groups was significant $(P<0.001)$. The frequency of the $T$ allele was lower in cervical cancer cases than in healthy controls (49.80 vs $55.00 \%)$. However, no statistically significant difference was observed between the two groups ( $P$ $=0.102$ ).

Table 1. Characteristics of cervical cancer patients and controls.

\begin{tabular}{|c|c|c|c|c|c|}
\hline & \multicolumn{2}{|c|}{ Cervical cancer patients } & \multicolumn{2}{|c|}{ Controls } & \multirow[b]{2}{*}{$\mathrm{P}$ value } \\
\hline & $\mathrm{N}$ & $\%$ & $\mathrm{~N}$ & $\%$ & \\
\hline \multicolumn{6}{|l|}{ Age } \\
\hline$\geq 60$ & 167 & 65.23 & 159 & 63.60 & 0.711 \\
\hline$<60$ & 89 & 34.77 & 91 & 36.40 & \\
\hline \multicolumn{6}{|c|}{ Smoking status } \\
\hline Ever & 67 & 26.17 & 39 & 15.60 & 0.004 \\
\hline Never & 189 & 73.83 & 211 & 84.40 & \\
\hline \multicolumn{6}{|c|}{ HPV status } \\
\hline $\mathrm{HPV+}$ & 217 & 84.77 & 5 & 2.00 & $<0.001$ \\
\hline HPV- & 39 & 15.23 & 245 & 98.00 & \\
\hline \multicolumn{6}{|c|}{ Age at primiparity } \\
\hline$\geq 25$ & 82 & 32.03 & 91 & 36.40 & 0.304 \\
\hline$<25$ & 174 & 67.97 & 159 & 63.60 & \\
\hline
\end{tabular}

Table 2. Genotypes and alleles frequencies of PD1 gene polymorphism (PD-1.5 C/T) among cervical cancer patients and controls.

\begin{tabular}{|c|c|c|c|c|c|}
\hline & \multicolumn{2}{|c|}{ Cervical cancer patients } & \multicolumn{2}{|c|}{ Controls } & \multirow[b]{2}{*}{$P$ value } \\
\hline & $\mathrm{N}$ & $\%$ & $\mathrm{~N}$ & $\%$ & \\
\hline \multicolumn{6}{|c|}{ Genotypes } \\
\hline $\mathrm{CC}$ & 45 & 17.58 & 62 & 24.80 & \multirow[t]{3}{*}{$<0.001$} \\
\hline $\mathrm{CT}$ & 167 & 65.23 & 101 & 40.40 & \\
\hline TT & 44 & 17.19 & 87 & 34.80 & \\
\hline \multicolumn{6}{|c|}{ Alleles } \\
\hline $\mathrm{C}$ & 257 & 50.20 & 225 & 45.00 & \multirow[t]{2}{*}{0.102} \\
\hline$T$ & 255 & 49.80 & 275 & 55.00 & \\
\hline
\end{tabular}

\section{Association of PD1 gene polymorphism (PD-1.5 C/T) with cervical cancer risk}

We found that the CT genotype was significantly associated with increased cervical cancer risk (adjusted $\mathrm{OR}=2.18,95 \% \mathrm{Cl}=1.37-6.11, \mathrm{P}=0.009$ ). However, the TT genotype was not significantly associated with cervical cancer risk (adjusted OR $=0.89,95 \% \mathrm{Cl}=0.67-2.29, \mathrm{P}$ $=0.363$ ). We found that $\mathrm{T}$ allele was not significantly associated with risk of cervical cancer (OR $=0.98,95 \% \mathrm{Cl}=0.67-1.71, \mathrm{P}=0.769)$. There was significant association between PD-1.5 C/T polymorphism and susceptibility to cervical cancer under dominant model $(\mathrm{OR}=1.27,95 \% \mathrm{Cl}$ $=1.01-2.15, \mathrm{P}=0.047$ ). However, there was no significant association between PD-1.5 C/T polymorphism and susceptibility to cervical cancer under the recessive model $(\mathrm{OR}=0.91,95 \% \mathrm{Cl}$ $=0.87-1.78, P=0.819$, shown in Table 3 ). 
Table 3. Association of PD1 gene polymorphism (PD-1.5 C/T) with cervical cancer risk.

\begin{tabular}{l|c|c|c|c}
\hline & Patients & Controls & OR (95\%Cl) & P value \\
\hline General genotype & \multicolumn{4}{l}{} \\
\hline CC & 45 & 62 & 1.00 (Reference) & \\
\hline CT & 167 & 101 & $2.18(1.37-6.11)$ & 0.009 \\
\hline TT & 44 & 87 & $0.89(0.67-2.29)$ & 0.363 \\
\hline Dominant genotype & 45 & 62 & 1.00 (Reference) & \\
\hline CC & 211 & 188 & $1.27(1.01-2.15)$ & 0.047 \\
\hline CT+TT & 212 & 163 & 1.00 (Reference) & \\
\hline Recessive genotype & 87 & 0.91 (0.87-1.78) & 0.819 \\
\hline CC+CT & 44 & 225 & 1.00 (Reference) & \\
\hline TT & 257 & 275 & $0.98(0.67-1.71)$ & 0.769 \\
\hline Allele frequency & 255 &
\end{tabular}

\section{DISCUSSION}

The etiology of cervical cancer is a complex, multistep, and multifactorial process. Although age of first intercourse, number of sexual partners, more parities, cigarette smoking, race, and low socioeconomic status are consistently shown as risk factors for cervical cancer, none of these has proven a significant and independent risk factor (Schoell et al., 1999). At present, it is widely accepted that infection of oncogenic human papillomaviruses (HPVs), predominantly HPV-16 and HPV-18, is the major risk factor for the development of cervical cancer (Franceschi, 2005). However, only a small proportion of such HPV-infected cases progress to cervical cancer (Walboomers et al., 1999), which indicates that HPV infection is a necessary, but not sufficient, condition to develop cervical cancer. Thus, other factors associated with increased susceptibility, such as genetic background, might be required. Recently, host genetic factors (and in particular, single nucleotide polymorphisms) are considered important determinants of the susceptibility of individuals to specific malignancies. The humoral immune system plays a crucial role in preventing and eliminating tumors, and can influence the development of cervical cancer. The most important anti-tumor immune response is mediated by $T$ lymphocytes. Therefore, it is logical to suspect that polymorphisms of immune response-related genes that regulate $\mathrm{T}$ lymphocyte activation and proliferation might contribute to cervical cancer pathogenesis. The PD-1 molecule, a receptor of the CD28 family, is a well characterized negative regulator of $\mathrm{T}$ cells through its delivery of inhibitory signals. It is expressed on peripheral CD4+ and CD8+ T cells, natural killer T (NKT) cells, B cells, and some dendritic cell (DC) subsets upon their activation (Keir et al., 2008). The human gene encoding PD-1 is located on 2q37.3. It encodes a 55-kDa typel transmembrane glycoprotein. The extracellular domain of PD-1 is an immunoglobulin-like structure and its cytoplasmic tail contains an immunoreceptor tyrosine-based inhibitory motif (ITIM). Interaction between PD-1 and its ligands PD-L1 (B7-H1; CD274) or PD-L2 (B7-DC; CD273) can activate the cytoplasmic ITIM of PD-1 and induce inhibitory signals that attenuate T-lymphocyte activation and proliferation, suppress cytokine secretion, induce $\mathrm{T}$ cell apoptosis, and maintain peripheral tolerance (Freeman et al., 2000; Latchman et al., 2001; Nishimura and Honjo, 2001). PD-L1 is highly expressed on a variety of solid tumors and its increased expression in carcinomas can contribute to tumor evasion of the immune system, thereby engendering a poor clinical prognosis (Blank et al., 2005; Dong et al., 2002; Ghebeh et al., 2006; Ohigashi et al., 2005; Thompson et al., 2006). 
Previously, Mojtahedi et al. (2012) found that the PD-1.5 C/T polymorphism was significantly associated with colon cancer. The frequency of the CT genotype was significantly higher in colon cancer patients than in control individuals (58.3 vs 44.8\%, Bonferroni corrected $\mathrm{P}$ value $=0.024 ; \mathrm{OR}=1.74 ; 95 \% \mathrm{Cl}=1.15-2.62$ ) (Mojtahedi et al., 2012). Hua et al. (2011) found that CT heterozygosity at the PD-1.5 loci was present at a lower frequency in breast cancer cases in comparison with controls $(P=0.004)$, and the frequencies of the $C C$ genotype and $C$ allele were higher in breast cancer cases $(P=0.003$ and $P=0.010$, respectively). Moreover, the CC genotype and $\mathrm{C}$ allele are potential risk factors in breast cancer (Hua et al., 2011). Savabkar et al. (2013) found that the PD-1.5 C/T polymorphism might affect the risk of gastric cancer and prognosis in an Iranian population.

In the present study, we detected three genotypes for the PD-1.5 C/T polymorphism, (including CC, CT, and TT) among Chinese Han women. The genotype distribution in the control group was in Hardy-Weinberg equilibrium. The frequencies of the three genotypes (CC, CT, and TT) in cervical cancer cases and controls were 17.58, 65.23, 17.19\% and 24.80, 40.40, and $34.80 \%$, respectively; the difference between the two groups was significant. We found that the CT genotype was significantly associated with increased cervical cancer risk. Moreover, there was a significant association between PD-1.5 C/T polymorphism and susceptibility to cervical cancer under the dominant model.

In conclusion, the PD-1.5 C/T polymorphism may be associated with increased risk of cervical cancer. The study also highlights the importance of conducting genetic association studies in different ethnic populations.

\section{REFERENCES}

Bertsias GK, Nakou M, Choulaki C, Raptopoulou A, et al. (2009). Genetic, immunologic, and immunohistochemical analysis of the programmed death 1/programmed death ligand 1 pathway in human systemic lupus erythematosus. Arthritis Rheum. 60: 207-218. http://dx.doi.org/10.1002/art.24227

Blank C, Gajewski TF and Mackensen A (2005). Interaction of PD-L1 on tumor cells with PD-1 on tumor-specific T cells as a mechanism of immune evasion: implications for tumor immunotherapy. Cancer Immunol. Immunother. 54: 307-314. http://dx.doi.org/10.1007/s00262-004-0593-x

Dong H, Strome SE, Salomao DR, Tamura H, et al. (2002). Tumor-associated B7-H1 promotes T-cell apoptosis: a potential mechanism of immune evasion. Nat. Med. 8: 793-800. http://dx.doi.org/10.1038/nm0902-1039c

Ferguson R, Ramanakumar AV, Koushik A, Coutlée F, et al.; Biomarkers of Cervical Cancer Risk Study Team (2012). Human leukocyte antigen $\mathrm{G}$ polymorphism is associated with an increased risk of invasive cancer of the uterine cervix. Int. J. Cancer 131: E312-E319. http://dx.doi.org/10.1002/ijc.27356

Franceschi S (2005). The IARC commitment to cancer prevention: the example of papillomavirus and cervical cancer. Recent Results Cancer Res. 166: 277-297. http://dx.doi.org/10.1007/3-540-26980-0 18

Freeman GJ, Long AJ, Iwai Y, Bourque K, et al. (2000). Engagement of the PD-1 immunoinhibitory receptor by a novel B7 family member leads to negative regulation of lymphocyte activation. J. Exp. Med. 192: 1027-1034. http:// dx.doi.org/10.1084/jem.192.7.1027

Ghebeh H, Mohammed S, Al-Omair A, Qattan A, et al. (2006). The B7-H1 (PD-L1) T lymphocyte-inhibitory molecule is expressed in breast cancer patients with infiltrating ductal carcinoma: correlation with important high-risk prognostic factors. Neoplasia 8: 190-198. http://dx.doi.org/10.1593/neo.05733

Hua Z, Li D, Xiang G, Xu F, et al. (2011). PD-1 polymorphisms are associated with sporadic breast cancer in Chinese Han population of Northeast China. Breast Cancer Res. Treat. 129: 195-201. http://dx.doi.org/10.1007/s10549$\underline{011-1440-3}$

Jemal A, Bray F, Center MM, Ferlay J, et al. (2011). Global cancer statistics. CA Cancer J. Clin. 61: 69-90. http://dx.doi. org/10.3322/caac.20107

Keir ME, Butte MJ, Freeman GJ and Sharpe AH (2008). PD-1 and its ligands in tolerance and immunity. Annu. Rev. Immunol. 26: 677-704. http://dx.doi.org/10.1146/annurev.immunol.26.021607.090331 
Latchman Y, Wood CR, Chernova T, Chaudhary D, et al. (2001). PD-L2 is a second ligand for PD-1 and inhibits T cell activation. Nat. Immunol. 2: 261-268. http://dx.doi.org/10.1038/85330

Magnusson PK, Sparén P and Gyllensten UB (1999). Genetic link to cervical tumours. Nature 400: 29-30. http://dx.doi. org/10.1038/21801

Mojtahedi Z, Mohmedi M, Rahimifar S, Erfani N, et al. (2012). Programmed death-1 gene polymorphism (PD-1.5 C/T) is associated with colon cancer. Gene 508: 229-232. http://dx.doi.org/10.1016/j.gene.2012.07.059

Nishimura $\mathrm{H}$ and Honjo T (2001). PD-1: an inhibitory immunoreceptor involved in peripheral tolerance. Trends Immunol. 22: 265-268. http://dx.doi.org/10.1016/S1471-4906(01)01888-9

Ohigashi Y, Sho M, Yamada Y, Tsurui Y, et al. (2005). Clinical significance of programmed death-1 ligand-1 and programmed death-1 ligand-2 expression in human esophageal cancer. Clin. Cancer Res. 11: 2947-2953. http:// dx.doi.org/10.1158/1078-0432.CCR-04-1469

Prokunina L, Castillejo-López C, Oberg F, Gunnarsson I, et al. (2002). A regulatory polymorphism in PDCD1 is associated with susceptibility to systemic lupus erythematosus in humans. Nat. Genet. 32: 666-669. http://dx.doi. org/10.1038/ng1020

Qian BP, Wang XQ, Qiu Y, Jiang H, et al. (2013). An exon polymorphism of programmed cell death 1 gene is associated with both the susceptibility and thoracolumbar kyphosis severity of ankylosing spondylitis in a Chinese Han population. J. Orthop. Sci. 18: 514-518. http://dx.doi.org/10.1007/s00776-013-0385-2

Safaeian M, Hildesheim A, Gonzalez P, Yu K, et al. (2012). Single nucleotide polymorphisms in the PRDX3 and RPS19 and risk of HPV persistence and cervical precancer/cancer. PLoS One 7: e33619. http://dx.doi.org/10.1371/ journal.pone. 0033619

Savabkar S, Azimzadeh P, Chaleshi V, Nazemalhosseini Mojarad E, et al. (2013). Programmed death-1 gene polymorphism (PD-1.5 C/T) is associated with gastric cancer. Gastroenterol. Hepatol. Bed Bench 6: 178-182.

Schoell WM, Janicek MF and Mirhashemi R (1999). Epidemiology and biology of cervical cancer. Semin. Surg. Oncol. 16: 203-211. http://dx.doi.org/10.1002/(SICI)1098-2388(199904/05)16:3<203::AID-SSU2>3.0.CO;2-C

Tahoori MT, Pourfathollah AA, Akhlaghi M, Daneshmandi S, et al. (2011). Association of programmed cell death-1 (PDCD-1) gene polymorphisms with rheumatoid arthritis in Iranian patients. Clin. Exp. Rheumatol. 29: 763-767.

Thompson RH, Kuntz SM, Leibovich BC, Dong H, et al. (2006). Tumor B7-H1 is associated with poor prognosis in renal cell carcinoma patients with long-term follow-up. Cancer Res. 66: 3381-3385. http://dx.doi.org/10.1158/00085472.CAN-05-4303

Walboomers JM, Jacobs MV, Manos MM, Bosch FX, et al. (1999). Human papillomavirus is a necessary cause of invasive cervical cancer worldwide. J. Pathol. 189: 12-19. http://dx.doi.org/10.1002/(SICl)10969896(199909)189:1<12::AID-PATH431>3.0.CO;2-F 